\title{
The acute effect of different specific warm-up intensity on one repeat maximum squat performance on basketball players
}

\author{
Özgür Eken ${ }^{\mathrm{ABCDE}}$ \\ Faculty of Sport Sciences, Physical Education and Sport Teaching, Inonu University, Turkey
}

Authors' Contribution: A - Study design; B - Data collection; C - Statistical analysis; D - Manuscript Preparation; E - Funds Collection

\begin{abstract}
Background Squat exercises have some advantages in terms of time, practice and energy costs. It is also an exercise and Study Aim method used in training plan in terms of development of jumping ability in basketball players. There are many factors that affect squat performance both positively and negatively. These factors can vary as warm up, psychological and physiological conditions. In addition, squat performance may vary depending on warm-up types and intensity. It was aimed to determine the effect of different specific warm-up intensities on 1-maximum repetition squat performance (1-RM) on basketball players.

Material and The sample group of the study consisted of 10 men (age: $22.90 \pm 1.44$ years, height: $188.10 \pm 8.06 \mathrm{~cm}$, body Methods $\quad$ weight: $77.92 \pm 13.41 \mathrm{~kg}$, BMl: $21.70 \pm 2.83$ ), who played basketball regularly for at least 3 years. This group performed 3 different specific warm up intensities on non-consecutive days. Warm up protocols were determined as follows: light jogging for only 5 minutes (NSW), light jogging and \% 40 intensity specific warm up (LISW), light jogging and \% 80 intensity specific warm up (HISW).

Results Participants' 1-RM squat performance was found to be statistically different between NSW (91.10 kg), LISW $(95.00 \mathrm{~kg}), \mathrm{HISW}(100,50 \mathrm{~kg})$ respectively $(\mathrm{p}<0.05)$. Additionally, 1-RM squat performance values were observed highest after HISW. Rate perceived exertion (RPE) and body temperature (BT) were found highest after HISW.

Conclusions: $\quad$ As a result of this study, HISW are recommended to basketball coaches and basketball players in order to get more performance before the squat movement.

Keywords: basketball, intensity, squat, warm-up
\end{abstract}

\section{Introduction}

Coaches and trainers often use maximum strength test to assess muscle fitness, monitor progress, provide motivation and develop individualized programs. With the help of qualified supervision and appropriate test guidelines, maximum strength test can be safe, effective and reliable method for assessing muscle fitness in athletes and non-athletes [1]. Although isokinetic and isometric tests are frequently used in the clinical settings, the 1 maximum repetition (1-RM) test using free weights can also be used to evaluate the strength of athletes and to determine strength imbalances. 1-RM is the maximum weight that can be lifted only once for a given exercise using an appropriate exercise technique [2]. However, there are several factors that affect the precision of 1-RM assessments. One of these factors is warm-up protocol [3]. Warm-up can increase the efficiency of muscle glycolysis and high-energy phosphate degradation during exercise by increasing muscle temperature, increase in muscle metabolism and muscle fiber conduction velocity, resulting in a positive change in muscle contractility following previous contractile activity of VO2 kinetics. It can improve muscle function by influencing muscle crossbridge cycle velocity and oxygen uptake kinetics [4].

There are many studies on type, duration and intensity of warm-up protocols in the literature $[5,6,7]$. In addition, it is observed that the specific warm-up, combine warm-up

\footnotetext{
(c) Özgür Eken, 2021

doi:10.15561/26649837.2021.0506
}

and dynamic warm-up are more preferred in the literature. It is seen that the literature on linear and lateral warm-up is in a vicious circle. Linear and lateral warm-up protocols; It includes warm-up protocols made in different planes. Specific warm-up includes movements specific to the sport branch. In the literature, it has been suggested that voluntary contractions from low intensity to high intensity, such as dynamic warm-up, before the implementation of sportive activity, can increase strength and performance by activating nerve-muscle activation [8-10].

The fact that knowing the acute effect of different warm-up intensities on 1-RM squat performance in basketball players guides trainers and athletes can be considered as an undeniable fact in terms of the importance of the study. In addition, the fact that a study in which the acute effect of warm-up protocols applied at different intensities in basketball players was measured on squat performance has not been found in the literature, further increases the importance of the study. The aim of the study is to determine the effect of specific warm-up at different intensities on 1-RM in basketball players. For this purpose, as the research hypotheses (1) it is thought that 1-MT squat value will be positively affected in favor of specific warm-up applied at $80 \%$ intensity.

\section{Material and Methods}

Participants

The sample group of the study consisted of 10 men (age: $22.90 \pm 1.44$ years, height: $188.10 \pm 8.06 \mathrm{~cm}$, 
body weight: $77.92 \pm 13.41 \mathrm{~kg}$, BMI: $21.70 \pm 2.83$ ), who played basketball regularly for at least 3 years. All participants were informed about possible risks and details before starting the study and a voluntary consent form was signed. In addition, the participants were asked to sleep for 7-8 hours before the tests. All test and measurement applied in this study were approved by the Institute's Clinical Research Ethics Committee (Approval Number: 2021-2228). All tests and training practices were performed at the same time of the day (09.00-11.00).

\section{Experimental Design of the Study}

In the study, the anthropometric measurements of the participants were determined. Measurements were made in the Sports Hall of the Faculty of Sports Sciences. All volunteers who agreed to participate in the study were informed in detail about the content of the study before the test. Before the application started, the participants were given necessary information about the content, place and time of the study. After the first warm-up ( 5 minutes of light-intensity aerobic jogging), specific warm-up protocols at different intensities were applied on nonconsecutive days under the supervision of the trainer. In addition, the participants performed 10 maximum repetitions (10-RM) tests in the session without specific warm-up. 10-RM was converted to 1 max rep (1MT) using Brzycki [11] equations.

$1 \mathrm{MT}=$ (Weight lifted/ (1.0278 - [0.0278 ×Repeats])
After specific warm-ups of different intensities, 5 minutes of passive rest was performed before 1-RM. This rest period was determined by considering the results of Willardson and Burkett [12] and Rahimi's [13] studies in which the effect of resting at different times on squat performance increased more after 5 minutes of rest. 24 hours before the tests, the participants were informed that they should not use heavy exercise, alcohol, caffeine, and should not use the ingredients in ergogen supplements.

\section{Warm-up Protocols}

No Specific Warm-up Phase (NSW)

After the participants were given detailed information about the test before the test started, the participants' maximum heart rate was determined [14]. Then, warmup rate of jogging each individual was calculated as 30$40 \%$ according to the heart rate [15]. Participants in the study were warmed up under the control of experts. In this way, both the warm-up intensity and the warm-up differences between the participants in the study were eliminated. When the heart rate was between 110-120 per minute after resting for 5 minutes, the maximum strength values of the participants were obtained by performing 1 repetition maximum $\left(1-\mathrm{RM}_{\max }\right)$ squat (Table 1) [11].

Low Intensity Specific Warm-up (LISW) (40\%)

Participants performed 10 repetitive squat exercises consisting of 1 set at $40 \%$ intensity after 5 minutes of jogging. After the specific warm-up, the participants

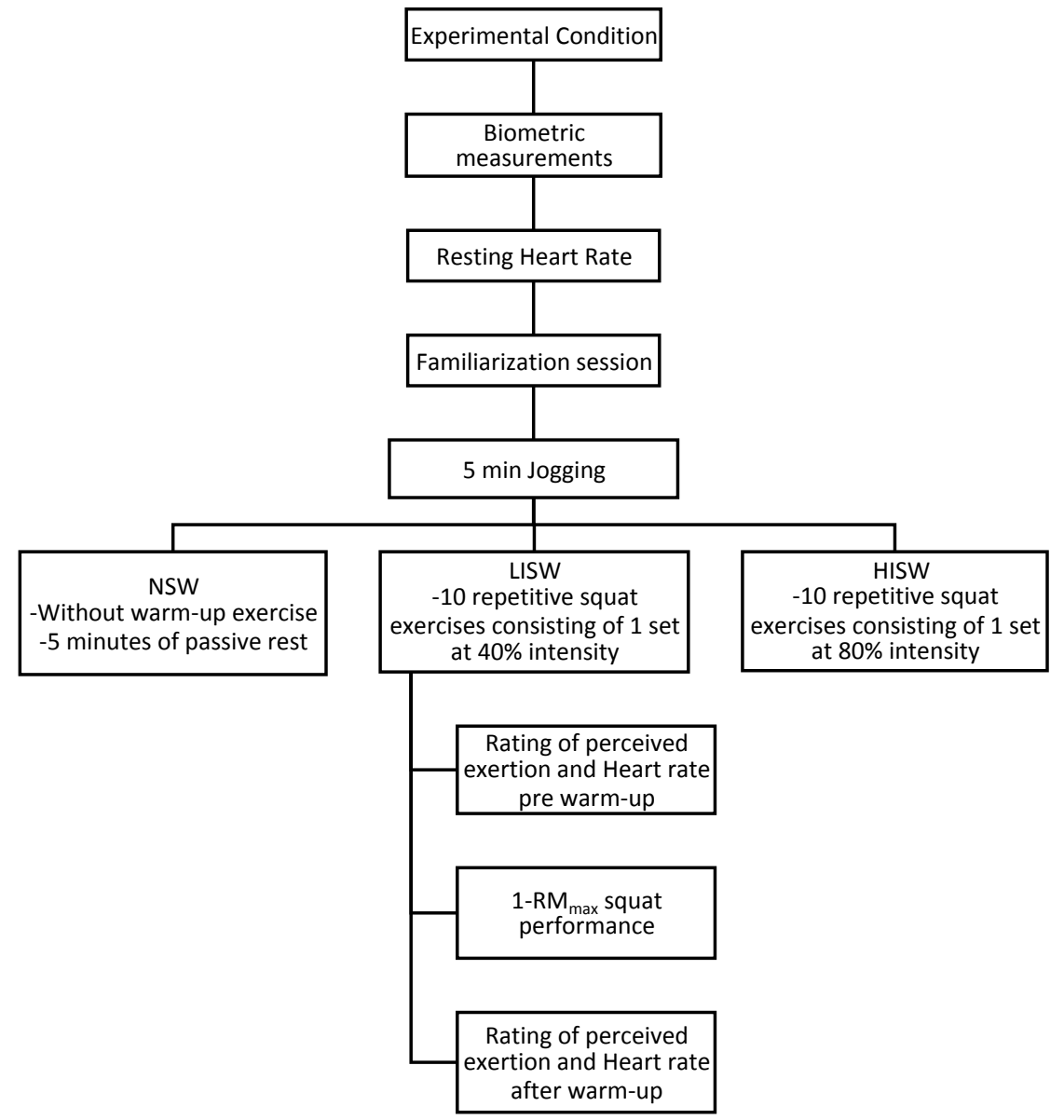

Figure 1. Experimental Design 
were allowed to repeat the movement by adding $2.5-5$ $\mathrm{kg}$ according to the weight they lifted and the level of difficulty they felt within the scope of 1 maximum squat repetitions obtained previously, and $1-\mathrm{RM}_{\max }$ squat values were determined. The weight gain process was continued until the participants could no longer perform 1 repetition, and the participants' $1-\mathrm{RM}_{\max }$ squat performance was observed (Table 1).

High Intensity Specific Warm-up (HISW) (80\%)

Participants performed 10 repetitive squat exercises consisting of 1 set at $80 \%$ intensity after 5 minutes of jogging. After warm-up, the participants were allowed to repeat the movement by adding $2.5-5 \mathrm{~kg}$ according to the weight they lifted and the level of difficulty they felt within the scope of 1-RM squat previously obtained, and 1-RM maximum squat values were obtained. The weight gain process was continued until the participants could no longer perform 1 repetition, and the participants' 1-RM squat performance was observed (Table 1).

Statistical Analysis

The obtained data were analyzed in SPSS (25.0) package program. "Repeated Measures Anova" was used to determine the effect of specific warm-up protocols applied at different intensities on 1-RM squat performance. "Bonferroni" analysis, one of the multiple comparison tests, was used to determine which warm-up protocol favored the performance. Mauchly Test was used for homogeneity of variances and Greenhouse-Geisser correction factor was used to correct for variances. The significance level was chosen as $\mathrm{p}<0.05$.

\section{Results}

In Table 2, the anthropometric and demographic values of the volunteers participating in the research are examined. As a result of this observation, it was determined that the mean age of the research group: $21 \pm 70$ (years), height: $180.10 \pm 8.06$ (cm), weight: $77.92 \pm 13.41$ (kg), body mass index (BMI): $21.70 \pm 2,83 \mathrm{~kg} / \mathrm{m}^{2}$.

When rate perceived exertion level (RPE) after warm-up is examined in Table 3, there is a significant difference between different warm-up intensities $(p<$ 0.05). Considering the differences between the groups, there is a significant difference between the RPE values after each warm-up at different intensity and after 1-RM. In addition, when AZD after $1 \mathrm{MT}$ is examined, there is a significant difference between different warm-up intensities $(\mathrm{p}<0.05)$.

In Table 4, 1-RM squat performances after specific warm-ups applied at different intensities were examined. The highest performance value is seen after warm-up at $80 \%$ intensity.

In Table 5, body temperature after specific warm-up applied at different intensities was examined. The highest temperature value was reported after warm-up at $80 \%$

Table 1. Warm-up exercises

\begin{tabular}{lll}
\hline NSW & LISW & HISW \\
\hline 5 minutes jogging & $\begin{array}{l}5 \text { minutes jogging }+40 \% \text { specific } \\
\text { warm-up intensity (10 reps) }\end{array}$ & $\begin{array}{l}5 \text { minutes jogging }+80 \% \text { specific } \\
\text { warm-up intensity (10 reps) }\end{array}$ \\
\hline
\end{tabular}

Note: LISW - Low Intensity Specific Warm-up; HISW - High Intensity Specific Warm-up

Table 2. Demographic and anthropometric values of the participants

\begin{tabular}{lll}
\hline Parameter & Mean & Standard Deviation \\
\hline Height $(\mathrm{cm})$ & 188.10 & 8.06 \\
Body Weight $(\mathrm{kg})$ & 77.92 & 13.41 \\
Age (years) & 22.90 & 1.44 \\
Body Mass Index $\left(\mathrm{kg} / \mathrm{m}^{2}\right)$ & 21.70 & 2.83 \\
Resting Heart Rate $(\mathrm{rpm})$ & 64.20 & 4.87 \\
\hline
\end{tabular}

Table 3. Rate perceived exertion (RPE) levels of the participants in terms of different warm-up intensities

\begin{tabular}{|c|c|c|c|c|c|c|}
\hline Parameters & Warm-up Intensities & Mean & SD & $\mathbf{F}$ & $\mathbf{p}$ & Bonferroni \\
\hline \multirow{3}{*}{$\begin{array}{l}\text { RPE } \\
\text { After Warm-up }\end{array}$} & $5 \min$ jogging (1) & 8.50 & .79 & \multirow{3}{*}{8.88} & \multirow{3}{*}{0.00} & $1-2(0.04)$ \\
\hline & $\begin{array}{l}5 \text { min jogging }+40 \% \\
\text { Intensity (2) }\end{array}$ & 10.90 & .83 & & & $1-3(0.00)$ \\
\hline & $\begin{array}{l}5 \text { min jogging }+80 \% \\
\text { Intensity (3) }\end{array}$ & 11.50 & .61 & & & $2-3(0.33)$ \\
\hline \multirow{3}{*}{$\begin{array}{l}\text { RPE After } \\
\text { 1-RM }\end{array}$} & $5 \min$ jogging (1) & 18.50 & .52 & \multirow{3}{*}{1.47} & \multirow{3}{*}{0.00} & $1-2(0.02)$ \\
\hline & $\begin{array}{l}5 \text { min jogging }+40 \% \\
\text { Intensity }(2)\end{array}$ & 17.50 & .52 & & & $1-3(0.00)$ \\
\hline & $\begin{array}{l}5 \text { min jogging }+80 \% \\
\text { Intensity (3) }\end{array}$ & 16.60 & .51 & & & $2-3(0.23)$ \\
\hline
\end{tabular}


Table 4. 1-RM values of participants in terms of different warm-up intensities

\begin{tabular}{|c|c|c|c|c|c|c|}
\hline Parameters & Warm-up Intensities & Mean & SD & $\mathbf{F}$ & $\mathbf{p}$ & Bonferroni \\
\hline \multirow{3}{*}{$\begin{array}{l}\text { 1-RM After } \\
\text { Warm Up }\end{array}$} & 5 min jogging (1) & 91.10 & 11.29 & \multirow{3}{*}{22.562} & \multirow{3}{*}{0.00} & $1-2(0.01)$ \\
\hline & $\begin{array}{l}5 \text { min jogging }+40 \% \\
\text { Intensity }(2)\end{array}$ & 95.00 & 12.24 & & & $1-3(0.00)$ \\
\hline & $\begin{array}{l}5 \text { min jogging }+80 \% \\
\text { Intensity ( } 3 \text { ) }\end{array}$ & 100.50 & 14.42 & & & $2-3(0.01)$ \\
\hline
\end{tabular}

Table 5. Body temperature (BT) of participants after different warm-up intensities

\begin{tabular}{|c|c|c|c|c|c|c|}
\hline Parameters & Warm-up Intensities & Mean & SD & $\mathbf{F}$ & $\mathbf{p}$ & Bonferroni \\
\hline \multirow{3}{*}{$\begin{array}{l}\text { BT After Warm } \\
\text { Up }\end{array}$} & 5min jogging (1) & 36.40 & 0.13 & \multirow{3}{*}{500.39} & \multirow{3}{*}{0.00} & $1-2(0.00)$ \\
\hline & $\begin{array}{l}5 \text { min jogging }+40 \% \\
\text { Intensity (2) }\end{array}$ & 36.83 & 0.13 & & & $1-3(0.00)$ \\
\hline & $\begin{array}{l}5 \text { min jogging }+80 \% \\
\text { Intensity ( } 3 \text { ) }\end{array}$ & 37.23 & 0.14 & & & $2-3(0.00)$ \\
\hline
\end{tabular}

Table 6. Heart rates (HR) of participants after different warm-up intensities

\begin{tabular}{|c|c|c|c|c|c|c|}
\hline Parameters & Warm-up Intensities & Mean & SD & $\mathbf{F}$ & p & Bonferroni \\
\hline \multirow{3}{*}{$\begin{array}{l}\text { HR } \\
\text { After Warm-up }\end{array}$} & 5 min jogging (1) & 133.30 & 4.37 & \multirow{3}{*}{163.76} & \multirow{3}{*}{0.00} & $1-2(0.00)$ \\
\hline & $\begin{array}{l}5 \text { min jogging }+40 \% \\
\text { Intensity }(2)\end{array}$ & 149.20 & 2.52 & & & $1-3(0.00)$ \\
\hline & $\begin{array}{l}5 \text { min jogging }+80 \% \\
\text { Intensity (3) }\end{array}$ & 162.60 & 3.27 & & & $2-3(0.00)$ \\
\hline
\end{tabular}

intensity.

In Table 6, HR after specific warm-up of different intensities is examined. The highest HR value is observed after warm-up at $80 \%$.

\section{Discussion}

This study shows that the warm-up protocol of different intensities before 1-RM $\mathrm{max}_{\operatorname{man}}$ can have a significant effect on squat performance in male basketball players. In the study, the $1-\mathrm{RM}_{\max }$ performances of the participants were determined by 5 minutes jogging $(91.10 \pm 11.29), 5$ minutes jogging $+40 \%$ intensity $(95.00 \pm 12.24)$ specific warm-ups and 5 minutes jogging $+80 \%$ intensity $(100.50$ $\pm 14.42)$ specific warm-ups. 1-RM squat performance after HISW increased by $5.5 \mathrm{~kg}(5.2 \%)$ compared to LISW. In

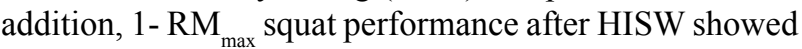
an increase of $9.4(8.5 \%) \mathrm{kg}$ compared to NSW. To our knowledge, no other study has investigated the acute effects of specific warm-ups at different intensities on 1$\mathrm{RM}_{\max }$ squat performance.

There are very few studies in the literature in which the acute effect of warm-up protocols on maximum squat performance has been determined $[5,7,10]$. Kafkas et al., [10] determined the effect of different warm-up protocols on 1-maximum repetition squat performance $\left(1-\mathrm{RM}_{\max }\right)$, and it was determined that 1-RM squat performance values increased the most after dynamic warm-up. Ribeiro et al.,
[5] found that the specific warm-up seems to enhance neuromuscular actions that enable a higher movement velocity during the first training repetitions and to allow greater peak velocities in less time. Çağlar et al. [7] reported that 1-RM squat strength after heel-assisted foam roller warm-up was higher than the strength measurement values after warm-up specific to heel-free strength. The results of the studies are that warm-up protocols and warm-up intensities can improve 1-RM performance. Santos et al. [16] compared the acute effect of different stretching protocols on the lower extremities using the sum of the maximum repetitions (RM) performed before the strength training session. Specific warm-up, static stretching, proprioceptive neuromuscular stretching and ballistic stretching were performed on 10 female jazz dancers. The results of the study showed that in the smith machine squat exercise, the ballistic stretching protocol had a significantly higher volume compared to all other protocols, while the PNF had a significantly higher volume compared to the specific warm-up. The results of the study showed that in the smith machine squat exercise, the ballistic stretching protocol had a significantly higher volume compared to all other protocols, while the PNF had a significantly higher volume compared to the specific warm-up. The positive effect of dynamic warm-up and ballistic stretching on performance can be supported by Bishop's [17] statement that active dynamic warm- 
up increases nerve conduction, improves speed-force relationship, improves agility performance, increases glycogenolysis and glycolysis. Aydın et al., [18] carried out the study to determine the effect of three consecutive sets of lower and upper body exercises at different repetitions on static stretching. In the study, 10 trained male athletes performed 3 sets of 10 repetitions of push down and leg extension exercises with $60 \%$ and $85 \%$ of 1 maximum repetition. Equal numbers of participants participated in the static stretching and non-stretching protocols. The results of this study showed that the number of repetitions decreased significantly after static stretching in two exercises of each intensity. Masamoto et al. [2] examined the acute effects of plyometric exercise on 1 maximum repetition (1-RM) squat performance in trained male athletes. Twelve male participants were evaluated in the 1-RM squat exercise during each of the 3 test sessions. Prior to all three trials, participants warmed up and performed static stretching on a fixed cycle for 5 minutes. Subjects then performed 5 sub-maximal sets of 1-8 reps before attempting a 1MT lift. In addition, the participants were waited for at least 4 minutes between 1MT trials. As a result of the study, it is shown that the drop jump performed before the $1 \mathrm{MT}$ test can increase the squat performance in trained male athletes.

In addition, there may be several mechanisms underlying warm-up intensity, warm-up protocols, and stretching protocols to alter 1-RM performance of plyometric training. Static stretching may influence neural mechanisms that could adversely affect muscular performance by reducing motor unit activation and muscle-tendon unit stiffness $[19,20]$. Also, theoretically, greater muscle activation for a given velocity may increase energy expenditure and therefore, accelerate the onset of fatigue [21]. Therefore, it can negatively affect 1-RM performance. The reason for the performance improvement after specific warm-up may be the increase in nerve conduction, the development of the velocityforce relationship, the increase in glycogenolysis and glycolysis, and the increase in the use of high-energy phosphate [17].

Some limitations of the study can be mentioned. First, the current study may have a single-sex design and a small number of participants. Second, this research was conducted for a specific type of exercise activity (1-RM); different exercise types (bench press, etc.) or different warm-up protocols (functional, combined, etc.), different types of sports (such as football, judo), different ages and women may produce different results.

\section{Conclusion}

Warm-up protocols performed by basketball players were effective in the positive development of 1-RM squat performances. Positive responses to HISW revealed that the increase in warm-up intensity in basketball players improved 1-RM performance more than other protocols in parallel. Basketball players and coaches must perform tests in multiple situations to establish consistent responses to different warm-up protocols and thus create their own individual and optimal warm-ups. However, the results are clear in showing a positive effect, so future research is needed to better understand the ideal nature of warm-up procedures for basketball players.

\section{Conflict of interest}

The author declare that there is no conflict of interest.

\section{References}

1. Baechle TR, Earle RW. Essentials of strength training and conditioning. 3th ed.Champaign: Human kinetics; 2008.

2. Masamoto N, Larson R, Gates T, Faigenbaum A. Acute effects of plyometric exercise on maximum squat performance in male athletes. The Journal of Strength and Conditioning Research, 2003; 17(1): 68-71. https://doi.org/10.1519/1533-4287(2003)017<0068:AEOPE $\mathrm{O}>2.0 . \mathrm{CO} ; 2$

3. Brown LE, Weir JP. ASEP procedures recommendation I: accurate assessment of muscular strength and power. Journal of Exercise Physiology Online, 2001; 4(3): 1-21.

4. Febbraio MA, Carey MF, Snow RJ, Stathis CG, Hargreaves M. Influence of elevated muscle temperature on metabolism during intense, dynamic exercise. American Journal of Physiology-Regulatory, Integrative and Comparative Physiology, 1996; 271(5): 1251-1255. https://doi.org/10.1152/ajpregu.1996.271.5.R1251

5. Ribeiro B, Pereira A, Alves AR, Neves PP, Marques MC, Marinho DA, Neiva HP. Specific warm-up enhances movement velocity during bench press and squat resistance training. Journal of Men's Health, 2021; 18: 1-8. https://doi.org/10.31083/jomh.2021.069

6. Kafkas A, Eken Ö, Kurt C, Kafkas ME. The effects of different stretching and warm-up exercise protocols on 50-meter swimming performance in sub-elite women swimmers. Isokinetics and Exercise Science, 2019; 27(4), 289-297.
https://doi.org/10.3233/IES-193141

7. Çağlar E, Uçan İ, Vural F. Acute effects of different warm-up protocols on squat force values: comparison of myofascial relaxation method and force-based warm-up methods. Beden Ĕ̈itimi ve Spor Bilimleri Dergisi, 2021; 23(1), 14-28. (In Turkish).

8. Faigenbaum AD, Bellucci M, Bernieri A, Bakker B, Hoorens K. Acute effects of different warm-up protocols on fitness performance in children. Journal of Strength and Conditioning Research, 2005; 19(2): 376-381. https://doi.org/10.1519/00124278-200702000-00010

9. Gelen E, Meriç B, Yıldız S. Acute effect of different warm-up protocols on sprint performance. Turkiye Klinikleri Journal of Sports Sciences, 2010; 2(1): 19-25. (In Turkish).

10.Kafkas ME, İlbak İ, Eken Ö, Çınarlı F, Yılmaz N, Kafkas AŞ. Acute effect of different warm-up protocols on 1-maximum rep squat performance. Spor ve Performans Araştırmalar Dergisi, 2018; 9(3): 192-205. (In Turkish).

11.Brzycki M. Strength testing-predicting a onerep max from reps-to-fatigue. Journal of Physical Education, Recreation and Dance, 1993; 64(1): 88-90. https://doi.org/10.1080/07303084.1993.10606684

12. Willardson JM, Burkett LN. A comparison of 3 different rest intervals on the exercise volume completed during a workout. The Journal of Strength and Conditioning Research, 2005; 19(1): 23-26. https://doi.org/10.1519/R-13853.1 
13.Rahimi R. Effect of different rest intervals on the exercise volume completed during squat bouts. Journal of Sports Science and Medicine, 2005; 4: 361-366.

14.Tanaka H, Monahan KD, Seals DR. Age-predicted maximal heart rate revisited. Journal of the American College of Cardiology, 2001; 37: 153-156. https://doi.org/10.1016/S0735-1097(00)01054-8

15.Karvonen MJ, Kentala E, Mustala O. The effects of training on heart rate: a longitudinal study. Annales Medicinae Experimentalis et Biologiae Fenniae, 1957; 35: 307-315.

16.Santos DTND, Mendes LT, Alves MDFDN, Bonela ACDC, Paz GA, Silva JBD, Miranda HL. Comparison of different flexibility training methods and specific warm-up on repetition maximum volume in lower limb exercises with female jazz dancers.JournalofHumanSportandExercise, 2018;(1):18-28. https://doi.org/10.14198/jhse.2018.131.03

17.Bishop DJ. Warm up II - Performance changes following active warm up and how to structure the warm up. Sports Medicine, 2003;33(7):483-498. https://doi.org/0112-1642/03/0007-0483
18.Aydın EM, Uçan Y, Yarar H. The acute effect of static stretching between sets on the number of repetitions performance in resistance training. Journal of Human Sciences, 2017; 14(4): 3913-3922. https://doi.org/10.14687/jhs.v14i4.4865

19.Kubo K, Kanehisa H, Fukunaga T. Effects of resistance and stretching training programmes on the viscoelastic properties of human tendon structures in vivo. The Journal of Physiology, 2002; 538: 219-226. https://doi.org/10.1113/jphysiol.2001.012703

20.Herda TJ, Cramer JT, Ryan ED, McHugh MP, Stout JR. Acute effects of static versus dynamic stretching on isomet- ric peak torque, electromyography, and mechanomyography of the biceps femoris muscle. Journal of Strength and Conditioning Research, 2008; 22: 809-817. https://doi.org/10.1519/JSC.0b013e31816a82ec

21.Lowery RP, Joy JM, Brown LE, De Souza EO, Wistocki DR, Davis GS, Wilson JM. Effects of static stretching on 1-mile uphill run performance. Journal of Strength and Conditioning Research, 2014; 28: 161- 167. https://doi.org/10.1519/JSC.0b013e3182956461

\section{Information about the author:}

Özgür Eken; https://orcid.org/0000-0002-5488-3158; ozgureken86@gmail.com; Inonu University, Faculty of Sport Sciences, Department of Physical Education and Sport Teaching, Malatya, Turkey.

Cite this article as:

Eken Ö. The acute effect of different specific warm-up intensity on one repeat maximum squat performance on basketball players. Pedagogy of Physical Culture and Sports, 2021;25(5):313-318. https://doi.org/10.15561/26649837.2021.0506

This is an Open Access article distributed under the terms of the Creative Commons Attribution License, which permits unrestricted use, distribution, and reproduction in any medium, provided the original work is properly cited (http://creativecommons.org/licenses/by/4.0/deed.en).

Received: 01.07.2021

Accepted: 26.08.2021; Published: 30.10.2021 